In support of an autosomal recessive inheritance pattern we have observed a sex ratio close to 1. Five cousin marriages are reported; however, it should be noted that these marriages are confined to ethnic groups with a high prevalence of consangunity. For the 21 families in whom complete up to date information was available the ratio of subsequently affected offspring to normal children after an initial affected child was $1: 4$. If the probable case from the family of patient 28 was included the ratio would be $1: 2 \cdot 7$ (expected ratio for an autosomal recessive condition $1: 3$ ).

Although the suggestion of autosomal recessive inheritance was made several years ago the question remains unresolved, possibly because parents limited the size of their families. In this series only six of the $\mathbf{2 1}$ families, for whom up to date information was available, have subsequently gone on to have further children. This may partly reflect the influence of an affected child on parental plans for further offspring which is not surprising as there is a high rate of mental retardation in survivors.
In conclusion paediatricians and geneticists should be aware that nesidioblastosis can be familial and is probably autosomal recessive. This is important both for genetic counselling and to enable a prompt diagnosis to be made in any subsequent affected sibling as delay in the institution of appropriate treatment may adversely affect outcome. Any further understanding of the genetic mechanisms in familial nesidioblastosis must await the recognition of a chromosomal or genetic marker.

1 Mckusick VA. Autosomal recessive phenotypes. Mendelian inheritance in man. 8th Ed. Baltimore: The Johns Hopkins University Press, 1988:1100.

2 Woo D, Scopes JW, Polak JM. Idiopathic hypoglycaemia in sibs with morphological evidence of nesidioblastosis of the pancreas. Arch Dis Child 1976;51:528-31.

3 Misugi K, Misugi N, Sotos J, Smith B. The pancreatic islet of infants with severe hypoglycaemia. Archives of Pathology 1970;89:208-20.

4 Moreno LA, Turck D, Gottrand F, Fabre M, ManouvrierHanu S, Farriaux JP. Familial hyperinsulinism with nesidioblastosis of the pancreas: further evidence for autosomal recessive inheritance. Am J Med Genet 1989;34: 584-6.

\title{
Increasing incidence of hypertrophic pyloric stenosis
}

\author{
P K H Tam, J Chan
}

\begin{abstract}
The incidence of pyloric stenosis in the Mersey region rose from $1.54 / 1000$ births in $1976-8$ to $2 \cdot 22 / 1000$ births in $1986-8$. Reliance on ultrasonography for diagnosis in the $1980 \mathrm{~s}$ resulted in fewer 'tumours' being felt; diagnostic delay was not shortened overall but serial ultrasonography showed evolving lesions in six patients. Clinical examination and selective use of ultrasonography is advocated.
\end{abstract}

An increase in the incidence of infantile hypertrophic pyloric stenosis was observed in several parts of this country in the late $1970 \mathrm{~s},{ }^{1-3}$ but it is not known if this trend was maintained in the 1980 s. The introduction of ultrasonography and its subsequent widespread acceptance for the diagnosis of pyloric stenosis has brought changes in clinical practice in the $1980 \mathrm{~s}$, but these changes have not been quantified. ${ }^{4} \mathrm{We}$ studied two cohorts of patients with pyloric stenosis in the Mersey region with a 10 year period separating them to identifying changes in the incidence and pattern of diagnosis.

\section{Patients and methods}

We conducted a retrospective survey of all patients with a confirmed diagnosis of infantile hypertrophic pyloric stenosis in the Liverpool and South Sefton areas of the Mersey region for the periods 1 April 1976-31 March 1978 and 1 April 1986-31 March 1988. Patients with pyloric stenosis in this region were all treated in the Royal Liverpool Children's Hospital; they were identified from the Hospital Activity Analysis data as well as the operating theatre records, and their hospital records were studied. Patients with pyloric stenosis referred to this hospital from other regions were excluded. Information on the birth rates in areas of the region during the study periods was obtained from Mersey Regional Health Authority.

Ultrasonography was not available in 1976-8, unlike 1986-8. There was no strict policy for referral for scanning, $72 \%$ of the patients being scanned, incuding most patients without a palpable 'tumour' and about half in whom the lesion was palpable.

The $\chi^{2}$ test was used for assessment of the significance of differences between groups, and a $p$ value of $<0.05$ was accepted as significant.

\section{Results}

The number of patients with pyloric stenosis, the incidence/1000 live births, the male:female ratio, the time from the onset of symptoms to hospital admission, the time from hospital admission to diagnosis and the number of palpable lesions recorded during the study periods are shown in the table. In addition, during the
Oxford OX3 9DU.

Accepted 9 December 1990

(Arch Dis Child 1991;66:530-1). 
Patients with pyloric stenosis between April 1976-March 1978 and April 1986-March 1988 in the Mersey region

\begin{tabular}{|c|c|c|c|}
\hline & $\begin{array}{l}1976-78 \\
(n=91)\end{array}$ & $\begin{array}{l}1986-88 \\
(n=146)\end{array}$ & p Value \\
\hline $\begin{array}{l}\text { Incidence/1000 live births } \\
\text { Male:female ratio } \\
\text { Mean (SD) time from onset of } \\
\text { symptom to admission (days) } \\
\text { Mean (SD) time from admission } \\
\text { to diagnosis (days) } \\
\text { Percentage that were palpable }\end{array}$ & $\begin{array}{l}1.54 \\
3.55: 1 \\
8.6(9) \\
0.9(1 \cdot 2) \\
91\end{array}$ & $\begin{array}{l}2 \cdot 22 \\
8 \cdot 35: 1 \\
9 \cdot 6(10) \\
0.8(1 \cdot 1)\end{array}$ & $\begin{array}{c}<0.01 \\
<0.05 \\
0.2 \\
0.5 \\
<0.001\end{array}$ \\
\hline
\end{tabular}

period 1986-8 there were six patients who had normal or equivocal initial ultrasonographic examinations but repeat scans after one to four days because of persistence of symptoms showed the typical features of pyloric stenosis. Two other patients had initial normal ultrasonographic scans but did not have repeat examinations; instead the diagnosis of pyloric stenosis was made by contrast studies. In the same period there were two patients who had a preoperative diagnosis of pyloric stenosis but at operation were found not to have a pyloric 'tumour'; the preoperative diagnosis had been made by clinical examination (palpable lesion) in one and by ultrasonography in the other.

\section{Discussion}

An increase in the incidence of infantile hypertrophic pyloric stenosis was recorded in central Scotland, ${ }^{1}$ the West Midlands, ${ }^{2}$ and South Glamorgan $^{3}$ in the late 1970s. No change in the incidence of the condition was observed in western Australia between 1971 and $1984 .^{5}$ Our figures suggest that there was a small increase in the incidence of pyloric stenosis in the Mersey region during the late 1980 s compared with the 1970 s. Our incidences of $1 \cdot 54 / 1000$ births in $1976-8$ and $2 \cdot 22 / 1000$ births in $1986-8$ were, however, low compared with the figures from Scotland, West Midlands and South Glamorgan (3.5-8.8/1000 births), ${ }^{1-3}$ and corresponded to those from Australia. 5 Yearly incidences of pyloric stenosis are known to fluctuate and the modest increase in incidence seen during the second period of our series may simply be part of this phenomenon. It has also been suggested that increased awareness of the condition may lead to hospital referral of mild cases that might otherwise have been managed conservatively in the community. ${ }^{6}$ The referral time in our series has remained unchanged in the past decade and gives little cause for such optimism. We have no explanation of the increased male preponderance in recent years in our series. The male:female ratio increased in the West Midlands ${ }^{2}$ and decreased in South Glamorgan ${ }^{3}$ in the late 1970s.

Our two study periods were separated by a decade during which ultrasonography was introduced and became easily available in our hospital. Has this practice led to earlier diagnosis? Overall, there was a significant change in the duration from hospital admission to diagnosis in the two periods in our series. The rate of palpable lesions dropped significantly during the second period of study. The most likely explanation is that clinicians are becoming overreliant on ultrasonography for diagnosis, with the risk that the skill and the motivation to 'feel for a pyloric tumour' are gradually being lost. Occasionally, particularly in some early cases of pyloric stenosis, ultrasonography may give a false negative diagnosis, but as the 'tumour' evolves, repeat ultrasonography often allows the diagnosis to be made. With both physical examination and ultrasonography there is also a small risk of false positive diagnosis. The high degree of sensitivity and selectivity of ultrasonography in the diagnosis of pyloric stenosis, however, should not be allowed to become an excuse for clinical complacency. Detection of a palpable lesion requires skill and patience. Clinicians should re-emphasise these virtues and aim to diagnose most cases of pyloric stenosis by clinical examination alone. Investigations, of which ultrasonography should be the first choice, will then be required only in selected circumstances.

We thank the Mersey Regional Health Authority for helping us to collect our data, and our clinical and radiological colleagues for allowing us to study their patients.

1 Kerr AM. Unprecedented rise in incidence of infantile hypertrophic pyloric stenosis. BMF 1980;281:714-5.

2 Knox EG, Armstrong E, Haynes R. Changing incidence of infantile hypertrophic pyloric stenosis. Arch Dis Child 1983;58:582-5.

3 Webb AR, Lari J, Dodge JA. Infantile hypertrophic pyloric stenosis in South Glamorgan 1970-9. Arch Dis Child 1983; 58:586-90.

4 Pilling DW. Infantile hypertrophic pyloric stenosis; a fresh approach to the diagnosis. Clin Radiol 1983;34:51-3. approach to the diagnosis. Clin Radiol 1983;34:S1-3. Hitchcock NE, Gilmour AI, Gracey M, Burke V. Pyloric stenosis in western Australia, 1971-84. Arch Dis Child

6 Meadow SR. Changing incidence of infantile hypertrophic pyloric stenosis. Arch Dis Child 1983;58:1035. 